Etnográfica

Revista do Centro em Rede de Investigação em

Antropologia

vol. 22 (1) | 2018

Vol. $22(1)$

\title{
Os colares de vidro de Quiatoni (México): suas agências e simetrias na prática museológica e antropológica
}

Glass necklaces from Quiatoni (Mexico): their agency and symmetry in anthropological and museological practices

\section{Andreia Martins Torres}

\section{(2) OpenEdition}

\section{Journals}

\section{Edição electrónica}

URL: https://journals.openedition.org/etnografica/5141

DOI: 10.4000/etnografica. 5141

ISSN: 2182-2891

\section{Editora}

Centro em Rede de Investigação em Antropologia

\section{Edição impressa}

Data de publição: 1 fevereiro 2018

Paginação: 27-51

ISSN: 0873-6561

\section{Refêrencia eletrónica}

Andreia Martins Torres, «Os colares de vidro de Quiatoni (México): suas agências e simetrias na prática museológica e antropológica», Etnográfica [Online], vol. 22 (1) | 2018, posto online no dia 17 maio 2018, consultado o 19 janeiro 2022. URL: http://journals.openedition.org/etnografica/5141 ; DOI: https://doi.org/10.4000/etnografica.5141

\section{(c) (†) 8}

Etnográfica is licensed under a Creative Commons Attribution-NonCommercial 4.0 International License. 


\section{Os colares de vidro de Quiatoni (México): suas agências e simetrias na prática museológica e antropológica}

\section{Andreia Martins Torres}

A proposta apresentada pretende refletir sobre a hermenêutica das narrativas históricas criadas em torno dos colares de vidro da comunidade zapoteca de São Pedro Quiatoni no contexto da museologia e da antropologia. Colocados em vitrines de museus, despojados do contexto que os relaciona com as pessoas que os usaram e do significado que tiveram para elas, esses objetos tornaram-se um instrumento para recriar o passado e reconstruir o presente sob determinados ideais. São essas ressignificações que ocorrem no interior de várias instituições, validadas pelo discurso histórico, que se tratará de recuperar. O objetivo é comparar essas imagens e agências com aquelas criadas pelo antropólogo durante o trabalho etnográfico na comunidade, ressaltando os seus limites e possibilidades num contexto de conflito de interpretações.

PALAVRAS-CHAVE: antropologia, museologia, agência, Quiatoni (Oaxaca-México).

Glass necklaces from Quiatoni (Mexico): their agency and symmetry in anthropological and museological practices - This work aims to reflect about the hermeneutics of the historical narratives created about the glass necklaces of the Zapotec community of San Pedro Quiatoni, in the context of museology and anthropology. Placed in museums, stripped off the context that relates them to the people who used them and the meanings they assumed, these objects have become a tool to recreate the past and rebuild the present under certain ideals. These resignifications that occur in various institutions, validated by historical discourse, is what we try to recover. The aim is to compare these images and agencies with those created by the anthropologist doing ethnographic work in the community, to emphasize its limits and possibilities in a context marked by conflicts of interpretation.

KEYWORDS: anthropology, museology, agency, Quiatoni (Oaxaca-México).

TORRES, Andreia Martins (andreiamtorres@gmail.com) - CHAM - Centro de Humanidades (NOVA FCSH e UAc), Portugal; Universidad Complutense de Madrid, Espanha. 


\section{INTRODUÇÃO}

Este artigo reflete sobre o conflito das interpretações produzidas pelo museu e pelo antropólogo, analisando a construção de narrativas discursivas sobre a história dos "colares de vidro de Quiatoni" em cada um desses âmbitos e entre eles. Como propõe Paul Ricoeur (1988), defende-se que a realidade se constitui simbolicamente na plurivocidade. O sentido dos símbolos materiais, como os colares, é diverso e depende de questões culturais que determinam a perceção e o seu entendimento por parte de cada indivíduo. Por isso, a análise centrar-se-á nas fases de construção dos seus significados, considerando por igual todas as vozes enunciadas.

Primeiramente, descreve-se o objeto e o seu carácter agentivo sobre a autora. Ao recuperar este conceito postulado por Alfred Gell (1998), depois da crítica que dele faz Howard Morphy (2009), entende-se que os materiais exercem influência sobre os interlocutores, despertando-lhes sensações das quais dificilmente se desprendem. A opção de tornar visível a voz pessoal parte do reconhecimento de que este texto, enquanto "estrutura de significação", se orienta por parâmetros culturais e interesses pessoais que interferiram nas escolhas realizadas e sugerem múltiplas interpretações. Por isso importa esclarecer que o recorte adotado esteve condicionado por uma formação em história e antropologia da América, mas também pelo facto de não ser mexicana.

Em seguida o enfoque recai sobre o discurso museológico e antropológico, com a mesma atitude referida anteriormente. Marcado pelo programa político das autoridades promotoras da investigação e salvaguarda do "património", esse discurso encontra-se subjugado a um ideal sobre a nação e a(s) sua(s) identidade(s). ${ }^{1}$ A intenção com que se funda o museu ou se orienta a pesquisa associa-se a relações de poder que se perpetuam no âmbito académico pelo controle de capital simbólico de uma comunidade estrangeira, nacional ou local (Bennett 2007; Combes 2012). Elas determinam a linha discursiva de ambas as disciplinas, bem como o lugar que ocupam os colares de vidro dentro da mesma. Nessas circunstâncias, os pesquisadores sofrem a sua agência e captam as manifestações de uma cultura material alheia, apropriando-se dela e concedendo-lhe uma nova aceção. Interpretar-se-ão essas dimensões expressas nas linguagens académicas para alcançar os seus sentidos figurados, ainda que os resultados estejam subordinados à experiência pessoal de quem os percebe.

Sobre a autoria, cabe referir que o "Grupo Solidario de Quiatoni", liderado por Eucario Angeles Martínez, desenvolveu várias iniciativas que conferem um 
papel ativo à comunidade nos procedimentos de patrimonialização de saberes e tradições locais, especialmente através da produção de vídeos (Smith 2008). Nesses registos, os colares dão forma às mulheres da região em narrativas encenadas, mas não abordam a sua história ou valor simbólico. Na academia, desconhece-se qualquer publicação de um antropólogo autóctone ou de um museu gerido pelas autoridades locais onde se espelhem as suas perspetivas. Isso apesar de os museus comunitários terem sido fundados no México a partir de 1984 e existir hoje um número considerável de instituições deste tipo. ${ }^{2}$ Ante a impossibilidade de aceder a uma narrativa "própria", produzida para "outros", resta a visão "oficial” das instituições geridas por instâncias políticas nacionais ou regionais, às vezes alheias às circunstâncias e demandas da população.

No que concerne ao discurso antropológico, consideraram-se as investigações publicadas e o relato da própria experiência de campo em São Pedro Quiatoni, entre os anos de 2011 e 2013.3 Ao assumir o papel de criador de novas narrativas, tentou-se gerar um distanciamento e evidenciar as limitações que conscientemente não se conseguiram contornar, para que o leitor identifique os pontos cegos deste texto.

Num terceiro momento reflete-se sobre o público que diariamente visita os museus e percebe os colares mediante o discurso do curador, como também o que lê o texto antropológico e intui essas peças pelo filtro do autor. Em ambos os casos, as narrativas atuam recursivamente sobre os sujeitos, que novamente transformam o objeto pelo filtro das suas circunstâncias culturais. Entre essas pessoas incluem-se "cidadãos comuns" e investigadores de diferentes áreas da "academia" que utilizam as ideias patenteadas para completar os seus relatos. Assim se vem constituindo uma certa uniformidade entre o discurso "popular" e o "científico", sem incluir verdadeiramente o "outro", o indígena de Quiatoni.

Por fim adotar-se-á uma postura simétrica (Latour 1991) para questionar a atividade do museólogo e do museógrafo, tal como a do antropólogo, ao patrimonializar os colares de Quiatoni nos museus nacionais e na comunidade. O objetivo é perceber até que ponto eles representam discursos plurais, se se

2 O final do século XX marcou uma mudança de paradigma na definição da identidade nacional. Se desde a época revolucionária estava fortemente atrelada a uma conceção hegemónica que exaltava a modernidade, na década de 80 surgiram várias iniciativas internacionais que promoveram a consideração da diversidade nacional. Nesse contexto cria-se o primeiro museu comunitário mexicano (em 1984) e, desde 2001, o Consejo Nacional para la Cultura y las Artes promove uma noção de "México: Nación Multicultural" (Rufer 2014a).

3 Vários pesquisadores se focaram nas comunidades zapotecas dos Vales Centrais (Lira Muñoz 2014; Muñoz Goetsch 2012; Gabarrot Arenas 2010; González 1994), mas poucos se interessaram especificamente por Quiatoni (Nuñez Matadamas 2011; Smith 2008; MacNabb e Rees 1993; Angeles Martínez 1989, 1997; Murphy 1989), e menos ainda foram os que realizaram algum tipo de reflexão sobre os colares. 
geram metaconflitos entre as suas normas de validação e de que maneira se poderiam contornar.

\section{OS COLARES DE VIDRO DE QUIATONI}

As peças em questão são adornos de uma volta ou duas meias voltas, compostas por um fio de fibra vegetal, normalmente henequén, com contas de vidro de diversos modelos e cores, intercaladas com uma espécie de pingentes alargados, de vidro soprado, e com uma argola na parte superior. O tamanho varia e, embora predomine a cor azul, existem exemplares verdes, transparentes, negros e rosados, normalmente translúcidos.

Lois Dubin (1987: 259) apresenta-as como uma das variantes introduzidas na América pelos espanhóis entre 1492 e 1600. Em traços gerais, é esta a ideia que prevalece no imaginário mexicano sobre a história das suas missangas. Elas associam-se aos conquistadores e à prática de "enganar" os indígenas, levando-os a trocar simples bugigangas por ouro.

Tais conjeturas aparecem corroboradas nas crónicas do século XVI que historiadores e arqueólogos citam para contextualizar os seus estudos (Castelló Yturbide e Mapelli Mozzi 1998: 19; Blair, Pendleton e Francis Jr. 2009: 74-1 19). Uma dessas obras é a Historia Verdadera de la Conquista de la Nueva España, de Bernal Díaz del Castillo, onde o "choque" intercultural durante a conquista se evidencia nas frustrações provocadas pela vigência de dois modelos monetários e duas escalas de valores: "y estábamos muy contentos con ellas [hachas], creyendo que eran de oro bajo, e los indios mucho más con las cuentas; mas todo salió vano que las hachas eran de cobre e las cuentas un poco de nada" (Díaz del Castillo 1974 [1576]: 28).

Poder-se-ia dizer que a ambivalência de certos materiais permitiu que ambos os sistemas se retroalimentassem satisfatoriamente para cada uma das partes, até que o ouro se tornou aí a referência monetária predominante, com a implementação do governo vice-reinal. Isso justifica o pedido de Gonzalo Guerrero quando Jerónimo de Aguilar tratou de resgatá-lo de entre os indígenas e levá-lo com os espanhóis:

"Hermano Aguilar, yo soy casado y tengo tres hijos, y tiénenme por cacique y capitán cuando hay guerras. Id vos con Dios, que yo tengo labrada la cara y horadadas las orejas. ¿Qué dirán de mí cuando me vean esos españoles ir de esta manera? Y ya veis estos mis hijitos cuán bonitos son. Por vida nuestra que me deis de esas cuentas verdes que traéis para ellos, y diré que mis hermanos me las envían por tierra" (Díaz del Castillo 1974 [1576]: 44).

De facto, o próprio Cortés, estando em San Juan de Ullúa, ofereceu o seu colar de contas a Montezuma por intermédio de Tendile, que disse ser o governador daquela província: 
“Luego Cortés mandó traer una silla de caderas con entalladuras de taracea y unas piedras margaritas, que tienen dentro de sí muchas labores, envueltas en unos algodones que tenían almizcle para que oliesen bien, y un sartal de diamantes torcidos, y una gorra de carmesí con medalla de oro de San Jorge, como que estaba a caballo con su lanza, que mata un dragón. Y dijo a Teñidle [sic] que luego enviase aquella silla en que se asiente el señor Montezuma.

Teñidle [sic] lo recibió y dijo que su señor Montezuma es tan gran señor que holgará de conocer a nuestro gran rey, y que le llevará presto aquel presente y traerá respuesta” (Díaz del Castillo 1974 [1576]: 64).

Tais perceções, que se repetem na voz popular e em expressões orais como "no vale un abalorio", ${ }_{4}^{4}$ repercutem diretamente na valoração de um tipo de pingentes de vidro que aparentemente se encontra apenas no México, no estado de Oaxaca. Assim se chegou ao município de São Pedro de Quiatoni, na região dos Vales Centrais (Tlacolula), viajando na "nuvem de Quiatoni" que todos os dias faz o transporte de pessoas entre a capital do município e a do estado.

\section{OS COLARES DE QUIATONI ENQUANTO MATÉRIA DE MUSEU E OBJETO MUSEOGRÁFICO}

Ao identificar os colares nos museus mexicanos, para perceber como se expunham e o que se dizia sobre eles, confirmou-se que na maioria dos casos não se aludia a Quiatoni. Eles davam consistência a narrativas sobre uma nação multicultural na qual o "indígena” ocupava uma posição controversa na história e cultura mexicanas. ${ }^{5}$ Sem reconhecer um processo histórico diferenciado a cada etnia, o discurso da sua participação na sociedade novo-hispana raramente distingue as particularidades de cada uma. ${ }^{6}$ A representação material do indígena aparece invariavelmente associada às contas de vidro, um símbolo icónico das dinâmicas do vice-reino. Nesse contexto, os referidos colares apresentam-se no museu como uma prova material dessas ideias, justificando a desconsideração pela filiação étnica no discurso recriado. Aqui tratar-se-á apenas de cinco dessas instituições: o Museo del Vidrio, em Monterrey; o Museo Regional Cuauhnáhuac, em Cuernavaca; e os três museus onde estas peças são expostas

4 Expressão registada pela primeira vez num dicionário de língua espanhola em 1726: "No vale un abalório. Locución para dár à entender que una cosa es despreciable, y de poco ò ninguna estimación” (RAE 1726: 5).

5 Sobre a formação da alteridade nos processos de criação de identidades nacionais e regionais, veja-se Claudia Briones (2008) e Mario Rufer (2014b).

6 Aspeto amplamente trabalhado por Roger Bartra (2004), Frida Gorbach (2012) ou Paula López Caballero (2008). 
em Oaxaca, ou seja, o Museo Berber Jiménez, que é particular, o Museo de las Culturas e o Museo Textil.

\section{Museo del Vidrio}

A instituição ocupa a antiga fábrica de Vidro de Monterrey, SA, fundada em 1909, em pleno auge da indústria cervejeira. Esta foi a primeira unidade industrial contemporânea dedicada à produção de vidro e a sua musealização ocorreu em 1989, abrindo ao público em 1992 com a missão de "resgatar, preservar e difundir a história do vidro no México, assim como promover uma cultura de apreço pelo vidro e incentivar a produção artística com este material". ${ }^{7}$

A narrativa é a de uma história linear, apresentando os materiais europeus anteriores à conquista para ilustrar a trajetória da produção vidreira e o tipo de peças usadas nas casas novo-hispanas. As primeiras salas servem de prefácio para associar a manufatura colonial ao conceito de arte popular. Tal ideia foi enunciada pela primeira vez em 1922, pelo Dr. Atl, na sequência das celebrações do Centenário da Independência. ${ }^{8} \mathrm{O}$ seu discurso assentou no facto de Puebla ser considerada a primeira cidade americana a produzir vidro e a exportá-lo para outras partes do continente. Por isso, "o segundo andar [do museu] está dedicado ao vidro popular e industrial" criado por autores anónimos ou reconhecidos". ${ }^{9}$ Esses objetos mostram-se como provas da excecionalidade mexicana durante a administração espanhola, mas sobretudo do engenho e arte da população, possibilitando a elevação dos seus produtos artesanais à categoria de objeto artístico. Esta tradição ancestral sobreviveu à independência, materializada simbolicamente no relato museológico possibilitado pela criação da fábrica.

O colar de Quiatoni expõe-se na primeira sala, ilustrando o uso indígena das contas europeias quando ainda não se produzia o vidro artificial na América:

"Colar de cristal de rocha, vidro e coral: aqui se pode disfrutar da beleza de uma peça especial. Trata-se de um colar datado de princípios do séc. XVI e que foi realizado por mulheres indígenas com contas de vidro veneziano (assim identificadas por estarem fabricadas com a técnica de millefiori). Este adorno possui elevado valor histórico e cultural, já que nele se fundem o trabalho das duas raças: a europeia e a indígena.

7 Do site do museu, em < http://www.museodelvidrio.com/museo/historia.htm > (última consulta em fevereiro de 2018).

8 O tema da exposição motivou uma publicação sobre as artes mexicanas. Na primeira edição (Murillo 1921) não se aborda o vidro, mas, no ano seguinte, o reconhecimento da ancestralidade desta manufatura e a sua vinculação ao universo "popular" levou à sua inclusão na segunda edição (Murillo 1922).

9 Do site do museu, em < http://www.museodelvidrio.com/museo/historia.htm > (última consulta em fevereiro de 2018). 
As contas chegaram às mãos dos indígenas, graças ao intercâmbio desigual que efetuavam com os primeiros colonizadores espanhóis. Os europeus ofereciam pedaços de vidro ou espelhos e em troca obtinham joias de ouro. Esta forma de troca era conhecida como a arte de 'margaritear', já que as contas venezianas tinham a forma de margaridas". ${ }^{10}$

A atribuição cronológica remete aos primeiros anos da conquista e à estafa perpetrada pelos espanhóis. Segundo o autor, as contas eram de Veneza, ignorando que ainda durante o período colonial a técnica de millefiori se empregava noutras regiões europeias para fazer um vidro à la façon de Venise (Cagno 2012; de Rochebrune 2004). Uma dessas regiões foi a de Barcelona, que manteve sempre contactos com Veneza, nomeadamente para exportar a barrilla usada na produção de vidro, como demonstram por exemplo José Gudiol Ricart (1941) e Justina Rodríguez García (1986, 1987, 1995). Sugere-se ainda que o colar foi montado por uma indígena, mas nada se diz acerca dela, nem se esclarece a etnia. Finalmente, associa-se a decoração das contas à flor margarida, vinculando-as à "arte de margaritear" que, na realidade, se referia ao comércio de pérolas no Caribe. ${ }^{11}$

\section{Museo Regional Cuauhnáhuac, Palácio de Cortés, Cuernavaca}

O museu foi fundado em 1974, num edifício mandado construir por Hernán Cortés em 1531. Erigido sobre as ruínas do senhorio de Cuauhnáhuac, ele funcionou inicialmente como sede do marquesado do Vale de Oaxaca e a sua sucessiva reutilização tornou-o o sítio idóneo para narrar a história do estado de Morelos, da época pré-hispânica à atualidade.

Aí se conservam dois colares de Quiatoni completamente alheios à história regional, que supostamente constitui o eixo da narrativa institucional. ${ }^{12}$ Colocados na sala das "Contribuições do Velho Mundo", junto de outros vidros utilitários, eles ilustram as mudanças tecnológicas introduzidas pelos espanhóis:

"A técnica do vidro foi encontrada desde as ruínas de Ocidente [referindo-se eventualmente ao Império Romano] pelos bizantinos e pelos povos do Próximo Oriente, onde a tomaram os árabes, para tornar a passá-la ao Oriente através de Veneza.

10 Do site do museu, em < http://www.museodelvidrio.com/museo/mppiso.htm > (última consulta em fevereiro de 2018), peça assinalada com o n. ${ }^{\circ} 2$.

11 Margarita é o mesmo que pérola, e no século XVIII designava os exemplares mais preciosos (RAE 1734: 498).

12 Segundo a classificação definida para os museus do Instituto Nacional de Antropología e Historia (INAH), os museus regionais "tienen como fin ilustrar el desarrollo histórico de la región, resaltando lo específico de dicho desarrollo, así como la diversidad cultural que lo caracteriza, además de constituirse en foros para la expresión de las manifestaciones de la cultura regional” (INAH 2009). 
Embora na época colonial as manufaturas estivessem rigorosamente controladas no México, o vidro foi trabalhado desde muito cedo.

Em 1743 [Juan] Villa Sánchez considerava sobre esta técnica [em Puebla] que: "[O vidro não se faz igual em parte alguma do reino], sim concorre com a [produção] de Veneza, é igual ao [vidro] de França, duplo terço, limpo, claríssimo e fabrica-se em peças de formas requintadas". ${ }^{13}$

A legenda alude aos inícios da produção de vidro no Oriente e aos intercâmbios técnicos que ocorreram, por meio dos "árabes”, entre esta região e Itália. Em seguida, coloca o espetador ante a notícia de que a produção de vidro na Nova Espanha começou cedo e escapou ao rigoroso controle da Coroa. Entende-se que o autor se refere às reformas borbónicas, quando se impuseram restrições ao desenvolvimento manufatureiro das províncias ultramarinas do Império. Deduz-se que a nova conjuntura não afetou o setor, constituindo uma exceção às dinâmicas económicas que predominaram a partir de meados do século XVIII. A investigação de arquivo realizada nos últimos anos (Torres $2016)$ e os trabalhos publicados por Peralta Rodríguez (2005, 2013) ou Miguel Ángel Fernández (1990) demonstram que efetivamente se mantiveram vários fornos de vidro em diferentes cidades, mas não se dispõe de informação suficiente para determinar se o setor sofreu algum retrocesso.

Os colares de Quiatoni apresentam-se como um símbolo da precoce produção de vidro na América e da qualidade que alcançaram as suas criações, citando a obra de Juan Villa Sánchez (de 1743) sobre Puebla sagrada e profana, publicada por Francisco Javier de la Peña (1835). Pareceria que essas peças se produziram na Nova Espanha, mas alguns dos exemplares estão compostos com moedas dos Estados Unidos Mexicanos, a modo de medalha, pelo que a sua execução é necessariamente posterior.

\section{Museo Belber Jiménez}

A exposição incide sobre uma coleção privada reunida desde 1965 pela norte-americana Ellen Belber e o oaxaquenho Francisco Jiménez, que vivem há muito tempo nos Estados Unidos da América. O governo local cedeu-lhes o edifício para expor desde 2008 uma amostra da arte popular mexicana, essencialmente joias e roupas indígenas, tanto antigas como contemporâneas, e obras de artistas consagrados (Talavera Benítez 2011).

No que concerne aos colares do tipo analisado, as legendas colocadas até 2013 remetiam ao passado colonial e aos intercâmbios desiguais, afirmando

13 Legenda exposta pelo menos entre 2010 e 2013 (ver < http://www.inah.mx/paseos/cuauhnahuad > , última consulta em fevereiro de 2018). A forma como está redigida é algo confusa e por isso optou-se por uma tradução literal, complementada com comentários e ampliações da referência textual de Villa Sánchez para facilitar a compreensão do texto. 
que as contas eram venezianas. As peças aparecem junto de outras produzidas por distintas comunidades zapotecas e mixes, sem uma ficha individual. $\mathrm{O}$ vetor que as une é a exaltação das artes populares dos povos de Oaxaca, ilustrando as suas expressões desde o período vice-reinal até às atuais, algumas inspiradas em objetos pré-hispânicos.

A coleção possui ainda um dos colares de Frida Khalo, que incorporou ao seu guarda-roupa vestidos e complementos indígenas, especialmente daquela região. Assim reivindicou uma mexicanidade que reinventou as expressões materiais dos vários grupos culturais do país para transformá-las em algo diferente. ${ }^{14}$ Esse é precisamente o mesmo princípio que subjaz ao colecionismo do emigrante indígena: os objetos do museu foram subtraídos das comunidades, legitimando-o o facto de o protagonizar uma pessoa da região. $\mathrm{Na}$ exposição, os seus proprietários originais estão completamente ausentes ou foram silenciados. A única expressão percetível é o gosto e o critério do casal que em parte pertence à comunidade, não a local (de Quiatoni) mas sim regional (de Oaxaca). Nesse sentido, este é o caso mais próximo de uma narrativa museológica de carácter comunitário acerca dos colares, ainda que o contexto fundacional e a sua gestão representem políticas opostas.

No final da exposição pode-se adquirir um original na loja e a um preço que poucas famílias na cidade conseguiriam pagar. De maneira subliminar, legitima-se publicamente o colecionismo e a sua perpetuação, em conivência com um comércio que se poderia designar desigual. Até certo ponto, a prática constitui uma extensão contemporânea do intercâmbio de contas por ouro durante a conquista, contrapondo novamente dois sistemas de valor e gerando uma relação que agrada a ambas as partes. Assim se revela uma das facetas da colonialidade, manifesta na sociedade mexicana nos museus, nas opções de seleção, construção e transmissão das memórias e identidades do país.

\section{Museo de las Culturas}

A coleção tem origem no antigo Museo Oaxaqueño, fundado em 1831 , e transformado em Museo Regional de Arqueología e Historia em 1933, ao integrar os achados arqueológicos da tumba 7 de Monte Albán. Em 1972 mudou-se para o Convento de Santo Domingo, com o nome de Museo de las Culturas. ${ }^{15}$

Os colares expõem-se na sala dedicada às "peças de engenho e destreza":

"A exposição que se apresenta é uma amostra da joalharia produzida em distintos povoados de Oaxaca e na própria capital. Yalalag, Juquilla, Tlacolula, Choapan e San Pedro Jicayan, entre outras [...] algumas das quais

14 Sobre a criação de uma dramaturgia da nação e das dimensões simbólicas da cultura mexicana, veja-se Ricardo Pérez Montfort (1999).

15 Ver < http://sic.gob.mx/ficha.php?table=museo\&table_id=105> (última consulta em fev. de 2018). 
datam da época colonial (1803), da jovem República (1853) ou do Porfiriatismo (1896). [...] Os colares e arrecadas são uma amostra da joalharia atual, recetora de história, engenho e destreza que se fazem presentes nestas peças". ${ }^{16}$

Destaca-se a ausência de qualquer referência a Quiatoni ou a como as peças incorporaram o acervo. A narrativa é próxima à das artes populares, transmitindo aspetos comuns a todas as comunidades da região, sem distinguir as particularidades de cada uma delas e contribuindo para o silenciamento do seu protagonismo histórico. ${ }^{17}$

\section{Museo Textil de Oaxaca}

Instalado numa casona da segunda metade do século XVIII, mandada construir por um comerciante de grana cochinilla, o museu associa o seu acervo à história deste corante têxtil. ${ }^{18}$

Em 2013 promoveu-se a exposição "Plata, vidrio y algodón: reflejos de la ciudad en los atuendos indígenas de Oaxaca”, com a curadoria de Alejandro de Ávila Blomberg, especialista em botânica que tem adotado um enfoque etnográfico nas suas investigações (De Ávila Blomberg e Martin 1990: 147-166). Além de trabalhar sobre a cochinilla (Sánchez Silva, De Ávila Blomberg e Recamier 2005), foi autor do catálogo de uma exposição sobre os têxteis mexicanos em Nova Orleães (De Ávila Blomberg 1980).

Em Oaxaca expôs as indumentárias tradicionais da região, enfatizando o seu carácter misto, ao conjugar elementos rurais e indígenas - o algodão com materiais urbanos - o vidro (De Ávila Blomberg 2013). Neste contexto, deteve-se nos colares de Quiatoni, solicitando ao Studio Xaquixe, em Etla, a produção de imitações para vender na loja do museu. ${ }^{19}$ A exposição foi muito bem montada e pela primeira vez associaram-se as peças às pessoas:

"Os colares [...] têm contas de vidro venezianas de distintos tipos, combinadas em alguns casos com contas pequenas de coral. [...] As anciãs que entrevistámos em 4 localidades desse município em 1985 recordavam que eram os comerciantes zapotecos de Mitla que os vendiam em Quiatoni.

16 Legenda exposta em 2011 e em 2013, quando se visitou o museu.

17 Repetidas vezes se contactou o museu para obter mais informações acerca das peças, mas as cartas entregues entre 2011 e 2013 não obtiveram resposta por parte dos vários diretores que a instituição teve ao longo desse período. Curiosamente, a exposição virtual disponível no site do INAH também não mostra os colares que, entretanto, poderão ter sido retirados (veja-se $<$ http://www.inah.mx/paseos/ MuseodelasCulturasdeOaxaca/ > última consulta em fevereiro de 2018).

18 Consulte-se o trabalho de Francisco López Ruiz (2012) ou o site do museu (em < http://www.mus eotextildeoaxaca.org.mx/historia.php > (última consulta em fevereiro de 2018).

19 Sobre a vinculação da patrimonialização aos museus e a mercantilização desses objetos associada ao turismo, veja-se Manuel Burón Díaz (2012). 
Sabia-se que adquiriam os corais na zona do Istmo de Tehuantepec enquanto que as contas de vidro se surtiam provavelmente na cidade de Oaxaca. Recordavam também que as mulheres de Quiatoni iam comprando os pingentes em lotes pequenos, conforme podiam pagá-los, para armar os seus colares. Chegavam a colocar-se até três colares juntos quando eram as festas. Supostamente os colares com pingentes pequenos eram para as meninas pequenas. Estes colares exemplificam a utilização de materiais importados através do comércio urbano para criar uma joia distintiva, que diferenciava a comunidade das vizinhas".

No entanto, a mensagem transmitida é idealizada. Quando o visitante vê essas peças, excecionalmente bem colocadas em manequins, as silhuetas que percebe são diferentes daquelas com que se cruza numa aldeia zapoteca. Embora a legenda indique que se trata de um "Traje de mulher para uso quotidiano, de San Pedro Quiatoni, comunidade zapoteca do distrito de Tlacolula, variante linguística dichsà, aprox. 1950" e que "O colar combina diferentes tipos de contas de vidro de Murano", atualmente nenhuma mulher se veste assim. Embora se tente romper com um discurso uniforme e realizar aquilo que Rita Segato (2002) designou como "alteridades históricas" para representar uma nação (ou região) multicultural, não se superou a ideia do indígena como uma figura "emblemática" constituída por signos diacríticos da diferença em relação aos "outros". Por isso, as roupas expostas no museu são as peças excecionais usadas outrora, com bordados "originais" e colares de vidro "únicos".

Apesar do esforço por recuperar processos e vivências passadas, estes condensam-se numa única imagem que não corresponde à do presente, nem a uma figura real do passado. Essa dinâmica espelha a incapacidade de reconhecer um processo histórico que implicou transformações no vestuário desse grupo. Sem superar verdadeiramente o discurso do "outro" como algo "exótico", um único manequim apresentava peças de períodos distintos que se relacionam com o indígena de "Quiatoni", ainda que ele nunca tivesse tido o aspeto apresentado na exposição. ${ }^{20}$

\section{A agência nos museus}

Os casos analisados sugerem que as opções de exibição seguem um modelo tradicional no qual as "coisas" expostas falam essencialmente acerca das pessoas que idealizaram a exposição, com uma margem reduzida para perceber outras dimensões da cultura material. O que elas dizem, através de como se exibem e complementam com fichas descritivas, são ideias gerais propagadas ao longo do tempo sobre a história das contas de vidro no México. Elas exaltam o valor e a excecionalidade das pessoas que conformam a nação, contrapondo a codícia 
do conquistador espanhol à singularidade das joias nativas, ou ainda à produção de um vidro novo-hispano de grande qualidade. O público mexicano, tal como o museólogo, está sobejamente familiarizado com essas abordagens que coincidem com as transmitidas na escola ou nas vozes populares. Tais narrativas confluem no museu, que oferece a prova material da sua veracidade. Para o estrangeiro, elas alimentam a perceção de diferença e atração pelo "exótico" mexicano, como consequência do discurso nacional que baseia a sua identidade numa capitalização do "étnico".

Salvo raras exceções, os colares são incapazes de expressar algo mais além das sensações estéticas que provocam no espetador. A narrativa do museu não orienta o visitante a refletir sobre quem os produziu e usou, pois o sujeito é quase sempre abstrato, situado num tempo e espaço pouco definidos. $\mathrm{O}$ único museu que os relaciona com Quiatoni é o Museo Textil de Oaxaca. Talvez isso se deva, em parte, às medidas de unificação do sistema de catalogação promovido pelo INAH e que levou à substituição dos antigos números de inventário por um novo registo de âmbito nacional. Muitas instituições não preservaram a referência antiga com o registo de entrada da peça. Noutros casos, os arquivos mortos acabaram por se perder em restruturações institucionais ou por desinteresse. Tudo isso contribuiu para a utilização das "coisas" materiais, tal como entende Latour, como simples ilustrações para narrativas concebidas a priori e não em diálogo com as peças ou os seus produtores/utilizadores. Assim, o coletivo híbrido de "coisas-pessoas" de que fala o antropólogo, neste caso, constitui-se pelos colares, os autores da exposição e aqueles que a percebem, mas pouco pelos seus criadores.

Se o visitante nacional dispõe de uma série de elementos narrativos acerca dessas peças que complementam o discurso no museu, para os estrangeiros, os colares ajudam a criar uma ideia acerca do "outro", o mexicano do passado e do presente. Essa ideia é complementada pela oferta de objetos de missangas produzidos por huicholes à porta das principais atrações turísticas. Alguns alcançaram grande reputação, como o "carocha" totalmente decorado com contas exposto primeiro no Museo de Arte Popular, na Cidade do México, e em 2012 no National Museum of American Indian, nos Estados Unidos da América. A atração pelo "outro" e as suas "curiosidades" está também na base da criação do Bead Museum, em Glendale (Arizona), que funcionou até 2011 . Entre a sua coleção de contas de todo o mundo incluíam-se colares de Quiatoni com o epíteto de "misteriosas contas", sintetizando como estas peças são percebidas e se dão a conhecer no estrangeiro para dar azo a novas imagens. Na legenda refere-se o casal Cordry, e é possível que eles tenham coletado esses colares em Oaxaca quando viajaram patrocinados por alguns museus. ${ }^{21}$ 
Apesar das lacunas documentais das instituições de salvaguarda mexicanas, o mais provável é que as peças tenham sido coletadas/doadas por antropólogos.

\section{OS COLARES DE QUIATONI ENQUANTO MATÉRIA ANTROPOLÓGICA}

\section{Os primeiros trabalhos}

A notícia mais antiga destes colares na narrativa antropológica é a de Donald e Dorothy Cordry. O interesse norte-americano pelas culturas mexicanas motivou o financiamento de expedições, em colaboração com o Museu Nacional de Antropologia (México), para coletar objetos de arte com valor etnográfico. A partir de 1941 o casal viajou a Oaxaca, onde se interessou pela indumentária dessas comunidades, publicando um livro com a foto de uma "jovem de Quiatoni vestindo um huipil de festa com um antigo bordado, e um colar de contas de vidro antigas" (Cordry e Cordry 1968). Mais tarde, Donald Cordry escreveu um pequeno artigo sobre os pingentes, explicando como foi informado de que procediam dessa comunidade zapoteca e como intuía serem do século XVII ou XVIII. Nos anos 1950-60 os "vendedores de curiosidades" (saqueadores) ofereciam-nos aos turistas junto às ruínas de Mitla, sendo ponderável que as contas tivessem sido coletadas em contextos arqueológicos coloniais. Ilustrando o texto, colocou outra foto da mulher com as mesmas roupas (Cordry 1975).

A imagem foi tomada por vários investigadores como representativa do uso destes colares pelas mulheres de Quiatoni. Apesar disso, em conversas com a linguista de zapoteco norte-americana Valerie Martínez, soubemos que:

"Mais recentemente, mostramos [ela e o seu marido Nicasio Martínes, de Oaxaca] a foto da jovem com o huipil, colar e brincos tradicionais (do livro dos Cordry) a um senhor de Quiatoni já aposentado que estava trabalhando com o meu marido. Ele admirou-se muito [de ver] a foto e por fim nos disse porquê. 'Ela é minha esposa!' Disse que estavam visitando amigos em Mitla (eles viviam então em Quiatoni e eram recém-casados), chegaram uns americanos, emprestaram a roupa, o colar, e os brincos à sua esposa, tiraram-lhe a foto e foram-se embora. Até [passado] muito [tempo] depois souberam que a foto estava no museu de Santo Domingo (embora nunca a tenha visto ali)" [e-mail trocado com Valerie Martínez a 18 de abril de 2013].

possível averiguar se inclui colares de Quiatoni ou se foram adquiridos pelo referido casal (Sáenz González 1944: 244). Donald Cordry é considerado um etnólogo sem formação académica, tendo trabalhado algum tempo no National Museum of American Indian (Nova Iorque) como coletor de peças etnográficas mexicanas, antes de se instalar no país. Muitas dessas obras encontram-se em vários museus e parte da sua coleção pessoal foi doada por Dorothy ao UCLA’s Museum of Cultural History, junto a marionetas de madeira feitas por Donald (Z. Dubin 1987; Sáenz González 1994: 244-245). 
Mary Davis e Greta Pack escreveram também sobre essas peças, mas pouco acrescentaram ao que já se sabia:

“Em São Pedro Quiatoni, uma pequena cidade ao sul de Oaxaca, as mulheres usam umas contas de vidro do séc. XVI pouco comuns [...]. Quiatoni não tinha estrada até recentemente e as contas ficavam na cidade onde passaram ao longo de gerações até as filhas começarem a viajar para cidades maiores e a vender os antigos colares" (Davis e Pack 1963: 88).

Regra geral, as publicações da época e posteriores perpetuam as mesmas ideias e raramente questionam os fundamentos da atribuição cronológica ou origem dos colares (Barba de Piña Chan 1960: 20; Davis 1975; Smith e Good 1982; Sayer 1985: 221; Francis 1987). Stephen Johnson (1975) sugere a possibilidade de as contas serem de Puebla, baseando-se na existência de uma manufatura de vidro desde 1542, mas não apresenta provas contundentes.

O panorama assinalado indica que o interesse da antropologia por essas peças surgiu de um fetichismo pelo "outro" que conduziu à formação de "coleções antropológicas" de origem não esclarecida. As referências aos vendedores de Mitla remetem a uma lógica semelhante à registada no Museu Belber Jiménez. A própria linguista já referida relatou como um vendedor lhe contou como "enganava" as mulheres de Quiatoni para as persuadir a desfazerem-se dos colares:

“E também nessa época (1990), quando estava de compras em Mitla nas lojas de artesanato, comecei a falar com o dono [de uma] enquanto as minhas amigas decidiam o que comprar. Ele contou-me que quando era jovem ia a Quiatoni vender e comprar. Iam caminhando durante três dias, ou mais se levavam animais para vender. Disse que quando via mulheres usando os colares tradicionais, lhes dizia, 'Porque querem usar esses colares? [Assim] parecem cabras!' E assim as convencia a vender-lhe os seus colares. Ele levava os colares a um lugar (não me quis dizer onde que já tinham passado muitos anos dessa época) na Cidade do México onde os compravam a bom preço. Quando estávamos falando, deu-me a entender que se arrependia de 'enganá-las' assim para que vendessem os seus colares" [e-mail trocado com Valerie Martínez a 18 de abril de 2013].

As primeiras publicações que trataram o tema criaram uma narrativa baseada em suposições declaradas como tal pelo antropólogo. Elas acabaram por se tornar verdades, chanceladas pelo cunho da publicação académica, mas, até hoje, não se encontrou este tipo de contas em contextos arqueológicos coloniais e desconhece-se a sua origem. As afirmações iniciais foram-se repetindo até há poucos anos, quando a investigadora Ana Nuñes Matadamas 
(201 1: 30) apresentou a sua tese de licenciatura na Escuela Nacional de Antropología e Historia.

Somando-se às imprecisões do texto, a foto dos Cordry que vem servindo para imaginar como seria uma mulher de Quiatoni com um colar "tradicional" é uma criação do antropólogo. Ambos os registos transmitem as expectativas do investigador e aquilo que ele foi capaz de imaginar sobre os adornos adquiridos fora da comunidade, mas muito pouco sobre as protagonistas que os portaram em seus corpos. Tal como no museu, elas estão ausentes.

\section{O trabalho de campo (2011-2013)}

O trabalho de campo em San Pedro Quiatoni tinha por objetivo identificar o uso dos colares. Imaginava-se que as contas deveriam ter um significado e que a composição original desses adornos se relacionava com alguns aspetos das suas crenças, e por isso pretendia registar tais narrativas.

Perceber que nenhuma mulher utilizava os colares nem se vestia como na foto dos Cordry ou como os manequins do Museo Textil de Oaxaca implicou uma enorme deceção. Eliza Santiago, uma jovem de Quiatoni, informou que antigamente as autoridades do município ofereciam um prémio às pessoas que se apresentavam com os seus trajes antigos durante as festas e localizaram-se algumas fotos em álbuns particulares. No entanto, a iniciativa não perdurou e com ela se extinguiu também a exibição dessas peças.

Ao longo das estadias na povoação urbana, conheci apenas duas pessoas que conservavam um colar deste tipo e que foram minhas interlocutoras.

María Cleotilde Martínez Nuñez é padeira e tem o seu forno no cimo de um dos cerros, entre outras construções de chapa e cartão. Num dos nossos encontros pedi-lhe que me falasse dos seus colares e se sabia de onde vinham. Respondeu-me então o que tantas outras pessoas já me tinham dito: que eram "muito antigos" e que não recordava desde quando se usavam. Na verdade, quando tentava obter uma resposta mais precisa, o pouco que ouvia era "quem sabe..."

Cleotilde não herdou essas peças da sua progenitora, comprou-as num rancho. $\mathrm{Na}$ altura, "há muito tempo", vinham de fora pessoas interessadas nos colares e ela deslocava-se até às casas mais afastadas procurando quem ainda os tivesse para os vender depois aos colecionistas. Comentou ainda, talvez justificando-se a si mesma, que essas mulheres já não utilizavam os seus adornos e que os davam às crianças para brincar porque faziam um "barulho bonito". Cleotilde não teria mais de 45 anos, não pôde ser uma das intermediárias do casal Cordry nos anos 1940-60. Ainda assim, a sua afirmação indica que existiu um comércio importante de colares de vidro durante as décadas posteriores, levando ao seu desaparecimento no seio da comunidade.

Confessou que guardou alguns colares por pensar que teriam valor, dada a enorme demanda de pessoas interessadas em adquiri-los. Segundo ela, 
deveriam ser "importantes" e por isso teriam que permanecer em Quiatoni. Há alguns anos, um professor propôs-lhe fazer um museu local com aquelas peças, mas a ideia, que a atraiu inicialmente, parece não ter tido o apoio das autoridades locais, uma vez que não chegou a ser colocada em prática.

Percebe-se assim como o interesse de "outros" (vendedores, colecionadores, antropólogos, professores, etc.) fez com que Cleotilde atribuísse aos colares o valor de expressão cultural. Ela atuou inicialmente como intermediária de um comércio de supostas antiguidades, para depois se transformar numa colecionadora, agora disposta a doar a sua "coleção" para transformá-la em "acervo" de um museu comunitário.

Outra das pessoas que preserva os adornos tradicionais de Quiatoni é María. A comunicação entre ambas ocorreu por meio do seu esposo, Juan, já que eu não falava zapoteco nem ela espanhol. O marido mostrou-se sempre envergonhado pelo seu suposto pouco domínio do idioma e, apesar de a nossa relação ter sido sempre marcada por um enorme carinho, a conversa nem sempre foi fluida. Os únicos dados que reuni foi que também a sua esposa comprara o colar, que não se tratava de uma herança familiar, mas que era "muito antigo". Disse-me que os brincos "de pombinha" se faziam com moedas antigas de prata que levavam a Oaxaca para que artesãos de Quiatoni as transformassem em joias. ${ }^{22}$

Soube que as minhas anfitriãs costumavam emprestar os seus colares às jovens que representavam a comunidade na Guelaguetza, em Oaxaca. A festa, criada em 1932 para celebrar o quarto centenário da fundação da cidade, perpetuou-se até à atualidade, todos os anos nas duas últimas segundas-feiras do mês de julho. O objetivo inicial era reunir pessoas dos oito grupos étnicos da região que, através das suas danças, música e indumentária, expressariam a pluralidade do estado e a "oaxacanidade". Os colares são um dos elementos com que as mulheres de Quiatoni se mostram aos "outros" e, associados às roupas, eles encarnam aquilo que os zapotecos desse município têm de particular e que os distingue dos demais oaxaquenhos. Isso embora não se usem no quotidiano, não cumprindo a função de constitutivos do corpo e da identidade dessas pessoas na sua vida diária, nem sequer para que os seus pares as vejam.

Durante o trabalho de campo pedi às minhas anfitriãs para as retratar com o colar, a fim de registar quem eram e que aspeto tinham as peças sobre os seus corpos. Esses registos gráficos são também idealizações minhas. Fui eu que lhes pedi para os colocarem para assim os documentar.

Cleotilde, que me contou a maior parte da informação reunida, pediu-me que a acompanhasse a casa. Tomou banho, colocou um vestido limpo e tirámos a fotografia (figura 1 ). 


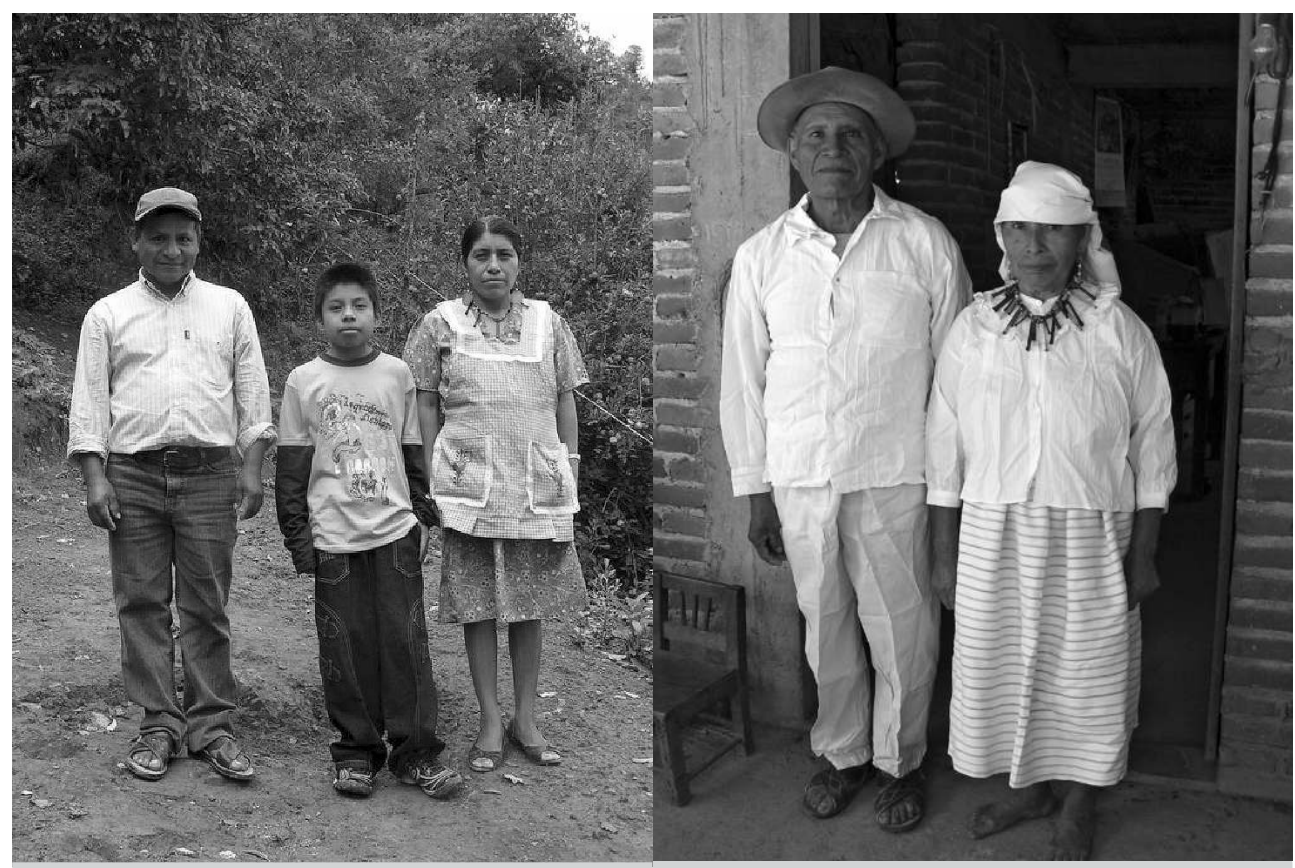

Figura 1 - Cleotilde Martínez Nuñez e família (2013).

Figura 2 - María e esposo (2011).

María ficou desconcertada com o pedido, sem entender a que me referia. Creio que para ela não tinha sentido mostrar-se a mim com o colar sem os outros elementos que constituem o que hoje se considera o "traje tradicional" de Quiatoni. Por isso vestiu-se com as joias, a blusa, a saia e um lenço na cabeça. Retratei-a junto ao seu esposo, que se vestiu de acordo com ela para a ocasião (figura 2).

Tentando diminuir a minha intervenção na composição e narrativa do "outro" na fotografia, resgatei antigos álbuns de família, entendendo esses testemunhos como autorretratos da comunidade. No de Felisberta Santiago López encontrei uma foto da festa de julho de 2004, quando ela posou junto ao marido (figura 3). Ambos se vestiam com a roupa de Quiatoni: ele com uma capa de chuva e ela com uma blusa bordada e uma saia de manta. Em outra foto, o casal aparece ao lado de María Nuñez Martínez, que conheci pessoalmente e que é mãe de Eliza Santiago, a quem já me referi (figura 4).

Ainda assim, os autorretratos da comunidade são também imagens encenadas. Eles expressam a forma de vestir e posar para se representarem numa figura recortada pelo enfoque do fotógrafo. É essa cena que pretendem congelar para depois recordar, ver-se e mostrar-se a outros. Ela contrasta com a que se percebe noutros retratos do "quotidiano", mesmo quando as pessoas e o local são os mesmos e não distam muito no tempo (figuras 3 e 5). Ambos são autênticos e refletem diferentes expressões da realidade de Quiatoni. 


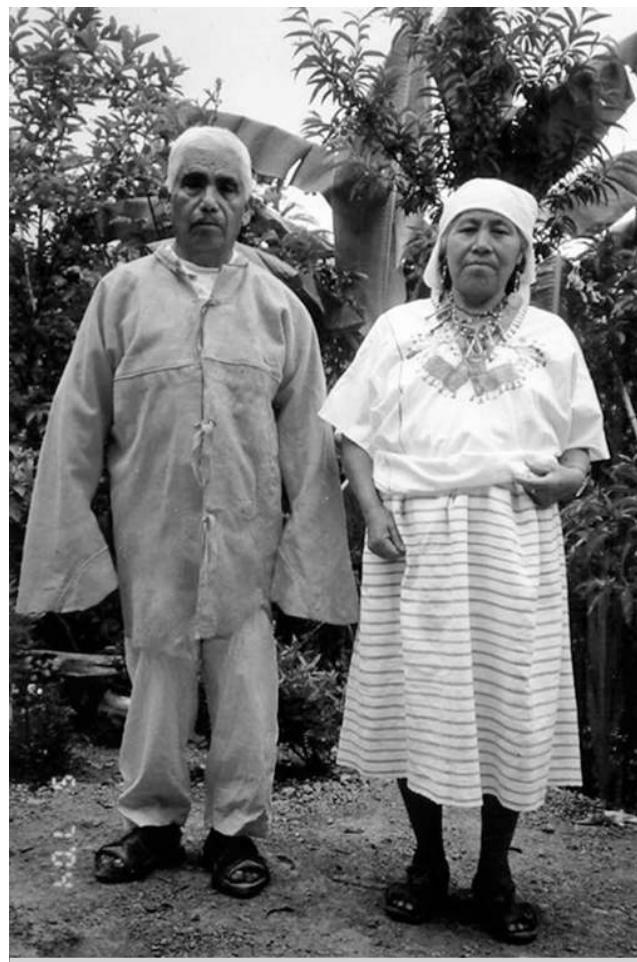

Figura 3 - Foto de álbum: Matheo Nuñez Martínez e Felisberta Santiago López (2004).

Embora não se averiguasse a origem dos colares e do seu uso, as descobertas feitas em Mitla, Tlacolula e Oaxaca por Valerie Martínez em 1990 fornecem importantes informações. Numa dessas cidades interpelou uma senhora de aproximadamente 70 anos, natural de Quiatoni, perguntando acerca dessas peças, que a "fascinavam desde que tinha visto a foto":

"Quando ela era jovem chegavam os vendedores com seus burros ou mulas vendendo todo tipo de coisas. Disse a velhinha que as missangas e contas estavam num baúzinho e a pessoa procurava os que lhe agradavam, comprando-os soltos para que cada uma [das mulheres] armasse 
o seu colar [da maneira] que mais gostava. Ela teve um colar mas quando cresceram os seus quatro netos dividiu o colar entre os quatro. (A sua filha, a mãe destes netos, tinha morrido e foi ela que se encarregou de criá-los.) Mostrou-nos umas missangas e contas" [e-mail trocado com Valerie Martínez a 18 de Abril de 2013].

A compra de contas avulso para compor colares e depois os vender observou-se ainda em 2011 , entre comunidades mixes da Serra de Oaxaca, nomeadamente em San Melchor Betaza. Esses exemplares vendem-se na localidade ou nos mercados semanais que cada dia se realizam num município diferente. Um dos que atrai mais gente é o de Yalalag, onde se observou como uma mulher vendia vários desses exemplares colocados numa cesta. Devido às circunstâncias não foi possível estabelecer uma relação de proximidade e conversar em espanhol sobre essas peças que trazia para vender.

\section{A agência no trabalho antropológico}

A investigação e o texto antropológico adotam opções e recortes para entender as "coisas", expressando as expectativas do investigador.

Durante o trabalho de campo tornou-se evidente o impacto do "outro" na perceção dos colares como "património cultural". Embora as minhas anfitriãs nunca visitassem os museus onde se exibem e não tivessem lido textos antropológicos, fizeram-no outros indivíduos que se deslocaram aí (ex.: médicos, professores) ou com quem falaram na cidade de Oaxaca (amigos, colecionadores, antropólogos). Esses diálogos levaram algumas mulheres a conservar as suas joias, simplesmente por considerarem que, se tinham valor para outros, deveriam ser também apreciados por elas. Percebe-se assim como, mais que um conflito de interpretações, o pensamento colonial atua na comunidade, subjugando o saber indígena ao académico. As relações entre ambos não constituem forças simétricas, mas ainda assim servem os interesses da população para reforçar os símbolos diacríticos da sua identidade. Eles reforçam a sua autoestima num contexto social e político onde os signos de diferença constituem a base de sistemas classificatórios que estabelecem uma hierarquia entre indigenidades. Os colares de vidro servem então para reivindicar a ancestralidade das suas tradições, legitimar a sua filiação indígena e manifestar a originalidade das suas expressões estéticas ou dos seus corpos.

\section{A MODO DE CONCLUSÃO}

A partir do estudo dos colares de Quiatoni, das suas narrativas no museu e na academia, evidenciou-se como as "coisas" são incapazes de falar por si mesmas tal como propunha Gell. Elas fazem-no através de quem as percebe, para expressar muitas outras coisas e pessoas, sempre e quando elas se ativam na 
memória dos seus interlocutores. Os materiais só têm voz própria na medida em que os seus aspetos formais podem ser percebidos, o que pressupõe a existência de um recetor. Em nenhum caso são agentivos porque, como afirma Howard Morphy (2009), não se podem mudar a si mesmos.

As agências no museu e na academia estabelecem um diálogo recursivo, criando uma espécie de "agência das agências". Isto torna difícil determinar as naturezas/entidades patentes nessas "coisas-pessoas" que a compuseram até ao presente em tais narrativas, ampliando a sua constituição fenomenológica ou as suas expressões na linguagem.

Neste caso, elas geraram processos de patrimonialização paralelos: um a nível nacional, nos museus geridos pelo INAH ou por particulares, e outro a nível local, protagonizado pelas mulheres de Quiatoni. Em ambos se transmite o gesto do colecionador, articulado permanentemente com as expectativas pessoais de quem exibe as peças no museu ou no seu corpo, e também do público. Ao estarem sujeitas a uma permanente atualização, vem-se alcançando uma visão mais ampla dessas peças que lhes acrescenta significados e transforma de novo o espetador.

Tudo isto faz pensar sobre os caminhos a seguir pela antropologia e a museologia, ou a interceção entre ambas. Nesses contextos, o conflito de interpretações é contornado através de um diálogo entre ambas as disciplinas sem uma verdadeira análise crítica dos postulados enunciados ou uma presença efetiva dos zapotecas de Quiatoni. Além da validade das interpretações académicas, é precisamente neste âmbito que se gera um metaconflito entre o conhecimento académico e o indígena. Ele oculta-se num equilíbrio instável entre forças às quais se atribuem pesos muito diferentes: se o primeiro não considerou a perspetiva indígena, o segundo incorporou argumentos alheios precisamente para validar o seu discurso e ser considerado para lá da comunidade.

As iniciativas que restituem ao indígena as suas coleções ao levá-los ao museu para falar sobre as suas peças e participar no trabalho curatorial da exposição (que ainda não foi adotado para as coleções analisadas) poderiam ser equiparadas ao autorretrato. Esse gesto constitui a tentativa de deixar o "outro" falar de si, de ele escolher o que quer mostrar e da maneira que lhe parece mais adequada. No entanto, tal como na construção da fotografia antropológica ou quando o indígena posa e escolhe a roupa, a exposição é uma encenação que oferece mais uma narrativa, silenciando outras. Como destacou Howard Morphy (2015), a agência das comunidades indígenas sobre objetos da sua cultura pode esconder as motivações dos formadores da coleção, bem como o papel que têm desempenhado no museu ao longo dos tempos sobre a mentalidade dos seus espetadores. Não sendo possível falar objetivamente do "outro" ou de "si mesmo", cabe explorar as possibilidades dessas ações performativas geradas nos encontros dentro do museu: entre a comunidade e o objeto, entre o pessoal do museu e essa nova agência que surgiu com a 
contribuição indígena, mas também entre a exposição e o público. Este último aspeto relaciona-se com o que o antropólogo Manuel Gutiérrez designou como "museu profano", ou seja:

"Este museo, que no es jerárquico, ni clasificatorio, ni pedagógico, que es cosmopolita y relativista es, en realidad, un museo no museístico. Es decir, es un museo en el que no se toma como natural la concordancia y unidad museográfica sino que, por el contrario, exhibe una pluralidad de lenguajes museográficos. La misma cosa - copias de la misma cosa - es tratada museográficamente de manera distinta: de tal modo que el interlocutor con esa cosa percibe con claridad todos los lenguajes museográficos posibles. Tiene presentes los problemas de la sintaxis. El museo innominado es, en este sentido un meta-museo (como la gramática constituye un meta-lenguaje)" (Gutiérrez Estévez 1998: 215).

Acredita-se que esta é uma solução para a exposição dos colares de vidro de Quiatoni. Assim se contornariam as dificuldades de sintaxe nas narrativas, expondo as peças de modo a expressar as múltiplas vozes que falam através delas: a do discurso histórico, a dos ditos populares, a dos indígenas de Oaxaca, a de outros mexicanos, ou mesmo a dos estrangeiros. Durante muito tempo, a grande discussão girou em torno da procura de equilíbrio entre a "coisa" e as "pessoas" que a constituem, mas a proposta assinalada pelo antropólogo é explorar todas as possibilidades que existem entre cada um dos extremos, tal como se tratou de fazer ao longo deste texto. Ela permite que o curador, depois de um esforço de identificar os múltiplos agentes que se relacionaram e continuam a relacionar com esses objetos, compile as suas narrativas e apresente a maior diversidade de relatos diretos relacionados com a interação entre os indivíduos e os materiais. Ainda que o recorte dessas "histórias" seja produzido pelo museólogo, aumentar-se-á a representatividade. Assim se superariam as dicotomias latentes no museu entre "nós" e "eles", "presente" e "passado", "verdadeiro" e "falso", construindo uma plataforma mais inclusiva que se aproxima um pouco desse conhecimento global inalcançável e em permanente construção de que fala Paul Ricoeur. Expondo a pluralidade de linguagens em pé de igualdade, reduz-se a hierarquização dos conhecimentos e saberes no museu. Evidentemente, uma exposição desta natureza necessita de permanentes atualizações devido ao carácter recursivo dos diálogos gerados no interior do museu e ao seu impacto no exterior.

As dinâmicas referidas poder-se-ão extrapolar à investigação académica, onde o conflito de interpretações entre as disciplinas e as populações poderá ser capitalizado para expressar, no âmbito da antropologia visual, diferentes realidades da relação entre o objeto e os vários sujeitos que interatuam de maneira direta ou indireta com ele. 


\section{BIBLIOGRAFIA}

ANGEles MARTíneZ, Eucario, 1989, Cultura y Producción: El Caso del Grupo Campesino Solidario de Quiatoni. Oaxaca, Dirección General de Culturas Populares.

ANGeles martíneZ, Eucario, 1997, Cuentos, Leyendas y Sucesos Históricos de Quiatoni. Tlacolula (Oaxaca), Ayuntamiento de San Pedro Quiatoni/Grupo Solidario Been Rguil Guialnzak.

BARBA DE PIÑA CHAN, Beatriz, 1960, “La joyería mexicana”, Artes de México, 165 (1): 5-48. BARTRA, Roger, 2004, "Sonata etnográfica en no bemol”, em El Museo Nacional de Antropología. 40. Aniversario. México, DF, Consejo Nacional para la Cultura y las Artes, 331-347. BENNETT, Tony, 2007, "Exhibition, difference and the logic of culture", em Ivan Karp et al. (orgs.), Museum Frictions: Public Cultures/Global Transformations. Durham, Duke University Press, 46-69.

BLAIR, Elliot, Lorann PENDLETON, e Peter FRANCIS Jr., 2009, The Beads of St. Catherines Island: Anthropological Papers of the American Museum of Natural History. Nova Iorque, American Museum of Natural History.

BRIONES, Claudia, 2008, "Formaciones de alteridad, contextos globales, procesos nacionales y provinciales”, em Claudia Briones (org.), Cartografías Argentinas: Políticas Indigenistas y Formaciones Provinciales de Alteridad. Buenos Aires, Antropofagia, 1 1-43.

BURÓN DÍAZ, Manuel, 2012, "Los museos comunitarios mexicanos en los procesos de renovación museológica", Revista de Indias, 72 (254): 177-212.

CAGNO, Simone, et al., 2012, "Composition of façon de Venise glass from early 17 th century London in comparison with luxury glass of the same age", em Wendy Meulebroeck et al. (orgs.), Proceedings of SPIE, 8422: 1-12.

CASTElló YTURBide, Teresa, e Carlota MAPElli MOZZI, 1998, La Chaquira en México. México, DF, Museo Franz Mayer.

COMBES, Annie, 2012, "Museums and the formation of national and cultural identities", em Bettina Messias Carbonell (org.), Museum Studies: An Anthology of Contexts. Oxford, Wiley-Blackwell, 260-272.

CORDRY, Donald, 1975, "Pendant glass beads from San Pedro Quiatoni, Oaxaca, Mexico", Bead Journal, 1 (4): 10-12.

CORDRY, Donald, e Dorothy CORDRY, 1968, Mexican Indian Costumes. Austin, Texas University.

DAVIS, Mary, e Greta PACK, 1963, Mexican Jewelry. Austin, Texas University.

DAVIS, Russel, 1975, “More on San Pedro Quiatoni Pendants", The Bead Journal, 2 (2): 1-2.

DE ÁVILA BlOMBERG, Alejandro, 1980, Catalog for an Exhibit of Mexican Textiles from the American Research Institute at the Department of Art Newcomb College. Nova Orleães, Middle American Research Institute, Tulane University.

De Ávila BlomberG, Alejandro, 2013, Plata, Vidrio y Algodón: Reflejos de la Ciudad en los Atuendos Indígenas de Oaxaca. Oaxaca, Museo Textil de Oaxaca, folheto da exposição.

DE ÁVILA BLOMBERG, Alejandro, e G.J. MARTIN, 1990, "Estudios etnobotánicos en Oaxaca”, em Enrique Leff, Julia Carabias e Ana Batis (orgs.), Recursos Naturales, Técnica y Cultura: Estudios y Experiencias para Un Desarrollo Alternativo. México, DF, Unam, 147-166. DE LA PEÑA, Francisco Javier, 1835, Puebla Sagrada y Profana: Informe Dado a Su Muy Ilustre Ayuntamiento el Año de 1746 por el M. N. T. Fray Juan Villa Sanchez, Religioso del Convento de Santo Domingo. Puebla, Casa del Ciudadano José María Campos. 
DE ROCHEBRUNE, Marie-Laure, 2004, "Venetian and façon de Venise glass in France in the 16 th and 17th centuries", em Jutta-Annete Page (org.), Beyond Venice: Glass in Venetian Style, 1500-1750. Nova Iorque, Corning Museum of Glass, 142-191.

DÍAZ DEL CASTILlO, Bernal, 1974 [1576], Historia Verdadera de la Conquista de la Nueva España. México, DF, Editorial Porrúa.

DUBIN, Lois Sherr, 1987, The History of Beads: From 30.000 b.C. to the Present. Nova Iorque, Adams.

DUBIN, Zan, 1987, "A bounty of mexican art and folk art", Los Angeles Times, 10 de julho.

FERnÁNDEZ, Miguel Ángel, 1990, El Vidrio en México. México, DF, Centro de Arte Vitro.

FRANCIS Jr., Peter, 1987, "San Pedro Quiatoni and Puebla glass", Margaretologist, l (4): 9.

GABARROT ARENAS, Mariana, 2010, "Origen es destino: capital social en comunidades zapotecas migrantes a Estados Unidos”, Trayectorias, 12 (30): 56-73.

GELL, Alfred, 1998, Art and Agency. Oxford, Clarendon.

GONZÁLEZ, Alvaro, 1994, Zapotecos de los Valles Centrales. México, DF, Instituto Nacional Indigenista.

GORBACH, Frida, 2012, "La 'historia nacional' mexicana: pasado, presente y futuro", em Mario Rufer (org.), Nación y Diferencia: Procesos de Identificación y Formaciones de Otredad en Contextos Poscoloniales. México, DF, Itaca-CONACyT, 105-122.

GUDIOL RICART, José, 1941, Monumenta Cataloniae, vol. 3: Los Vidrios Catalanes. Barcelona, Alpha.

GUTIÉRREZ ESTÉVEZ, Manuel, 1998, “Diálogo intercultural en el museo: silencios, malentendidos y encasillados", Anales del Museo de América, 6 (1): 205-215.

INAH - Instituto Nacional de Antropología e Historia, 2009, Capacidad de Desarrollo Administrativo y Calidad: Conocimientos básicos del INAH. México, DF, Coordinación Nacional de Recursos Humanos, disponível em < http://gobiernodigital.inah.gob.mx/Proyectos/ servicio_profesional_carrera/temp/conocimientos_basicos_INAH.pdf $>$ (última consulta em fevereiro de 2018).

JOHNSON, Sthephen, 1975, "The intriguing mystery of the Quiatoni Beads", The Bead Journal, 1 (4), 13-16.

LATOUR, Bruno, 1991, Jamais Fomos Modernos: Ensaio de Antropologia Simétrica. Rio de Janeiro, Editora 34.

LIRA MUÑOZ, Margarita, 2014, Vendedoras Zapotecas: Materialidad y Comercio en Un Mercado Periódico de los Valles Centrales de Oaxaca. México, DF, Universidad Nacional Autónoma de México, tese de mestrado.

LÓPEZ CABALLERO, Paula, 2008, "Wich heritage for wich heirs? The pre-Columbian past and the colonial legacy in the National History of Mexico", Social Antropology, 16 (1): 329-345.

LÓPEZ RUIZ, Francisco, 2012, "Museos textiles en Canadá, Guatemala y México", Res Mobilis, 1 (1), 107-123.

MACNABB, Valerie Ann, e Martha REES, 1993, "Liberation or theology? Ecclesial base communities in Oaxaca, Mexico", Journal of Church and State, 35: 723-750.

MATOS MOCTEZUMA, Eduardo, 1972, Manuel Gamio: Arqueología e Indigenismo. México, DF, SEP.

MATOS MOCTEZUMA, Eduardo, 1992, Breve Historia de la Arqueología en México. México, DF, Secretaría de Relaciones Exteriores. 
MENESES LOZANO, Hector Manuel, 2014, “Traditional innovation in Oaxacan Indigenous costumes”, em Textile Society of America Symposium Proceedings. Lincoln, University of Nebraska, disponível em < http://digitalcommons.unl.edu/tsaconf/903 > (última consulta em fevereiro de 2018).

MORPHY, Howard, 2009, "Art as a mode of action: some problems with Gell's Art and Agency", Journal of Material Culture, 14 (1): 5-27.

MORPHY, Howard, 2015, "The displaced local: multiple agency in the building of museums ethnographic collections”, em Kylie Message e Andrea Witcomb (orgs.), The International Handbooks of Museum Studies: Museum Theory. Chichester, Wiley-Blackwell, 365-388.

MUÑOZ GOETSCH, Beatriz, 2012, La Sombra del Mundo: Escenarios Zapotecos de Teatralidad Social e Interacción Ritual. Madrid, Universidad Complutense de Madrid, tese de doutoramento.

MURILlo, Gerardo (Dr. Atl), 1921, Las Artes Populares en México, vols. 1-2. México, DF, Cultura.

MURILlo, Gerardo (Dr. Atl), 1922, Las Artes Populares en México, vols. 1-2. México, DF, Cultura, 2. ${ }^{\mathrm{a}}$ edição revista.

MURPHY, Arthur, 1989, "Field notes from San Pedro Quiatoni", The Baylor Line. Wako, Baylor University, setembro: 12-13, 55-56.

NUÑEZ MATADAMAS, Ana, 2011 , Los Habitantes del Territorio Encantado: Construcción y Apropiación del Espacio entre los Zapotecos del Valle de Oaxaca. México, DF, Escuela Nacional de Antropología e Historia, tese de licenciatura.

PERALTA RODRÍGUEZ, José Roberto, 2005, “Desarrollo de la óptica y uso de anteojos en la ciudad de México durante los siglos XVI-XVIII”, Secuencia, 62 (1): 6-44.

PERALTA RODRíGUEZ, José Roberto, 2013, "Vidrieros de la ciudad de México en el siglo XVIII: sitios de producción y comercialización”, Procesos Históricos: Revista de Historia y Ciencias Sociales, 23 (12): 2-25.

PÉREZ MONTFORT, Ricardo, 1999, "Un nacionalismo sin nación aparente (la fabricación de lo "típico" mexicano (1920-1950)", Política y Cultura, 12: 177-193.

RAE - REAL ACADEMIA ESPAÑOLA, 1726, Diccionario de la Lengua Casttelana, vol. 1. Madrid, Imprenta de Francisco del Hierro.

RAE - REAL ACADEMIA ESPAÑOLA, 1734, Diccionario de la Lengua Casttelana, vol. 4. Madrid, Imprenta de la Real Academia.

RICOEUR, Paul, 1988, O Conflito das Interpretações: Ensaios de Hermenêutica. Porto, Rés Editora.

RODRÍGUEZ GARCÍA, Justina, 1986, El Vidrio Veneciano de los Siglos XV al XVII y Su Influencia en Cataluña. Madrid, Universidad Nacional de Educación a Distancia, tese de doutoramento.

RODRÍGUEZ GARCÍA, Justina, 1987, "La influencia del vidrio de Venecia en Cataluña", Annales du 10. ${ }^{\circ}$ Congrès de l'Association Internationale pour l'Histoire du Verre. Amesterdão, Association Internationale pour l'Histoire du Verre, 421-432.

RODRÍGueZ GARCÍA, Justina, 1995, "La façon de Venise en Castilla", Espacio, Tiempo y Forma, serie 4, 8 (1): 49-61.

RUFER, Mario, 2014a, "Paisaje, ruina y nación: memoria local e historia nacional desde narrativas comunitarias en Coahuila”, Cuicuilco, 21 (61): 103-136.

RUFER, Mario, 2014b, “La exhibición del otro: tradición, memoria y colonialidad en museos de México", Antíteses, 7: 94-120. 
SÁENZ GONZÁLEZ, María Olga, 1994, "Del tianguis al museo: el arte popular mexicano en colecciones norteamericanas y europeas”, em AAVV (eds.), México en el Mundo de las Colecciones de Arte: México Contenporáneo, vol. 1. México, DF, Azabache, 241-287.

SÁNCHEZ SILVA, Carlos, Alejandro DE ÁVILA BLOMBERG, e Bernardo RECAMIER, 2005, La Grana y el Nopal en los Textos de Alzate. México, DF, Consejo Nacional para la Cultura y las Artes.

SAYER, Chloe, 1985, Mexican Costume. Londres, British Museum Publications.

SEGATO, Rita, 2002, "Identidades políticas/alteridades históricas: una crítica a las certezas del pluralismo global", Runa: Archivo para las Ciencias del Hombre, 23 (1): 239-275.

SMITH, Laurel, 2008, "The search for well-being: placing development with indigenous identity”, em Pamela Wilson e Michele Stewart (orgs.), Global Indigenous Media: Cultures, Poetics, and Politics. Durham e Londres, Duke University Press, 183-196.

SMITH, Marvin, e Mary GOOD, 1982, Early Sixteenth Century Glass Beads in the Spanish Colonial Trade. Greenwood, Cottonlandia Museum.

TAlavera BeníteZ, Luis Fernando, 2011, Oaxaca: Patrimonio Cultural de México, vol. 1. México, Conaulta.

TORRES, Andreia Martins, 2016, "Vidro novo-hispano: uma fórmula europeia com ingredientes indígenas", em Caderno de Resumos do XII Encontro Internacional da ANPHLAC. Campo Grande, Universidade Federal do Mato Grosso do Sul, 44. 